\title{
EFEITOS PSICOTERAPÊUTICOS EM UM PARTICIPANTE DE UM ATO SOCIONÔMICO
}

\author{
Claudia Clementi Fernandes ${ }^{1,2, *}$ (iD)
}

\begin{abstract}
RESUMO
Partindo da experiência de um psicodrama público realizado no Centro Cultural São Paulo, em 2018, evidencio os efeitos psicoterapêuticos de atos socionômicos públicos. Destaco um participante deste trabalho, o qual trouxe o tema protagônico e foi atendido individualmente ao longo de quatro sessões psicoterapêuticas para a elaboração do vivido, reafirmando a efetividade do trabalho. No ato socionômico em questão, utilizamos a linguagem teatral, peça fundamental do dispositivo criado pelo grupo Gota D'Água, como norteador do trabalho. Inicialmente visto como dispositivo de intervenção socioeducativa, defendo, neste artigo, seu potencial psicoterapêutico. Nessa perspectiva, este trabalho é, sobretudo, uma reafirmação da ação dramática entendida como mola propulsora para um trabalho que transita entre o artístico e o psicoterapêutico.
\end{abstract}

PALAVRAS-CHAVE: Teatro; Ato socionômico; Psicodrama público; Psicoterapia.

\section{PSYCHOTHERAPEUTIC EFFECTS ON A PARTICIPANT IN A SOCIONOMIC ACT}

\section{ABSTRACT}

This article aims to highlight the psychotherapeutic effects of public socionomic acts. A public psychodrama experience took place at the São Paulo Cultural Center in 2018. One of the participants in this act, which brought the protagonist theme in an intense way, was later individually attended to during four psychotherapeutic sessions. During individual consultations, it was possible to elaborate what was experienced in public psychodrama, reaffirming the effectiveness of the work. In the socionomic act in question, we used theatrical language, a fundamental part of the device created by the Gota D'Água group, as a guide for the work. Initially seen as a socio-educational intervention device, I defend, in this article, its psychotherapeutic potential given by the dramatic action.

KEYBOARDS: Theater; Socionomic act; Public psychodrama; Psychotherapy.

\section{EFECTOS PSICOTERAPÉUTICOS EN UN PARTICIPANTE EN UN ACTO SOCIONÓMICO}

\begin{abstract}
RESUMEN
Este artículo tiene como objetivo resaltar los efectos psicoterapéuticos de los actos sociales económicos públicos. A partir de una experiencia de psicodrama público, realizada en el Centro Cultural São Paulo en 2018, se destaca la actuación de un participante, quien trajo el tema protagonista y, posteriormente, fue atendido individualmente durante cuatro sesiones psicoterapéuticas. Durante las consultas individuales, se pudo elaborar lo vivido en el psicodrama público, reafirmando la efectividad del trabajo. En el acto socionómico en cuestión, utilizamos el lenguaje teatral, parte fundamental del dispositivo creado por el grupo Gota D’Água, como guía para el trabajo. Visto inicialmente como un dispositivo de intervención socioeducativo, defiendo, en este artículo, su potencial psicoterapéutico combinado con la acción dramática.
\end{abstract}

PALABRAS CLAVE: Teatro; Acto socionómico; Psicodrama público; Psicoterapia.

1.Instituto Sedes Sapientiae - Departamento de Psicodrama - São Paulo (SP), Brasil.

2.Grupo de Teatro Espontâneo Gota D'Água - São Paulo (SP), Brasil.

*Autora correspondente: fernandescaca.fernandes@gmail.com

Editora de seção: Oriana Hadler

Recebido: 02 Fev 2021 | Aceito: 18 Jun 2021 


\section{INTRODUÇÃO}

Nos psicodramas públicos realizados no Centro Cultural São Paulo (CCSP), os dramas individuais se articulam às questões coletivas trazidas pelo grupo Gota D'água, promovendo um compartilhamento intenso de experiências entre os participantes. Tais atos socionômicos têm um caráter social porque envolvem o grupo em questões relacionadas à pólis, às contradições que vivemos, e tocam em questões de âmbito privado, conflitos, impasses da vida dos participantes que ali estão.

No palco psicodramático, a criação coletiva feita em ato ata-se e desata-se no espaço público, tece novos caminhos aos conflitos, aos sofrimentos individuais e coletivos. A partir da experiência com o grupo Gota D'água, digo que os atos realizados no CCSP articulam aspectos intrapsíquicos e interpsíquicos, ou seja, o grupo "trata" o indivíduo por meio dos conteúdos que, ali trabalhados, são transformados e ressignificados pelas dores e pelas questões dos participantes.

A intimidade do protagonista, isto é, daquele que expõe o seu drama privado, é resguardada por personagens e papéis psicodramáticos e acolhida no contexto grupal. Assim, essa intimidade do protagonista somente é revelada com a proteção do contexto dramático, o que possibilita, segundo Mascarenhas (2008 como citado em Davoli, 2012, p. 182), trabalharmos "com a inclusão de pessoas sociometricamente periféricas sempre por meio de implicação, isto é, da coexperiência, da coexistência e cocriação". Ainda de acordo com Merengué (2007 como citado em Davoli, 2012, p. 183):

Aquilo que o individuo sofre na chamada intimidade muito possivelmente é sofrido por tantos outros individuos, de alguma maneira, dentro de uma mesma cultura e de uma sociedade. A fronteira entre público e privado é derrubada para que possamos reconhecer que a bumanidade nos aproxima.

É nessa intersecção entre público e privado que este trabalho se insere, considerando público como um espaço de expressão grupal no qual os participantes manifestam múltiplas expressões de sofrimento psíquico, e como privado o modo com que temas coletivos tocam intimamente os sujeitos. Mascarenhas (2008, p. 63) ainda define o âmbito público "como uma determinada caraterística do instrumento grupal do psicodrama, o fato de ser aberto, não processual".

Fundamentado nesse potencial diálogo entre o público e o privado, este trabalho tem como objetivo relatar os efeitos psicoterapêuticos em um participante do ato socionômico. Os efeitos psicoterapêuticos são compreendidos conforme o que Aguiar (1988, p. 40) nomeia como "vias" de transformação:

- Ação do próprio sujeito orientada por diretrizes facilitadoras de mudanças;

- Desvelamento do coinconsciente (trazer para a consciência), e vivenciá-lo com intensa emoção, sintetizá-lo e expressá-1o;

- Produção de novos sentidos;

- Liberação de espontaneidade.

\section{MÉTODO: O DISPOSITIVO DO GRUPO GOTA D'ÁGUA}

A metodologia utilizada baseou-se no trabalho que já desenvolvo com o grupo Gota D'água, um tipo de metodologia socionômica que se utiliza de uma dramaturgia disparadora como inspiração de cenas espontâneas.

Segundo Rodrigues (2008), em seu quadro de referência para intervenções grupais, o trabalho do Gota D'água, assim como o de outros grupos, pertence à modalidade "obra de arte disparadora", pois utiliza uma obra ou peça teatral para disparar a ação dramática. A modalidade, segundo a autora, estrutura a tarefa comum de um grupo e é usada como um método, ou seja, uma dramaturgia que guarda certa universalidade e funciona como obra aberta, propositalmente "inacabada", questionadora da condição humana. A primeira encenação dos atores, tecida na harmonização entre gestualidades e palavras, tem o objetivo de disparar o trabalho coletivo que, por sua vez, segue com pressupostos do teatro espontâneo.

No trabalho com o grupo Gota D’água, em nossas direções disparadoras, procuramos estimular a cena dramática, em sua potência máxima apostando no surgimento de novos sentidos para quem está dentro ou fora dela, ou seja, evocando as 
múltiplas versões e vozes que aparecem em diálogos com a cena e podem coexistir. Cortes, pausas, ressonâncias, fluxos de cenas, outras cenas, nomeações diversas.

Ao investirmos no fluxo da repetição, no eco das palavras sínteses, nas gestualidades emergentes, esse fluxo de cenas pode vir a nos surpreender e se impor como desvio, surpresa, novidade. As cenas espontâneas de um único fluxo caminham em direção ao inédito, à saúde e, portanto, ao efeito terapêutico do trabalho. $\mathrm{Na}$ busca pela espontaneidade, a produção grupal reafirma a experiência singular do sujeito no mundo.

Nesse sentido, colocamos em foco a vertente poética de um instante, de um gesto, de um sorriso, de um abraço ou de um choro, enfim, de qualquer detalhe que possa fazer girar, transformar e levar os participantes a responder de maneira inédita a antigas situações. Nesse lugar estão os efeitos psicoterapêuticos e clínicos de nosso trabalho. Fazer clínica na cena psicodramática é sair da psicopatologização dos indivíduos, ou seja, abandonar a ideia de "conserto" dos sujeitos e entender a prática clínica como não dissociada do social, do trabalho criativo que acompanha a ação-transformação. Essa perspectiva norteia nosso trabalho.

\section{O ATO SOCIONÔMICO}

$\mathrm{O}$ ato socionômico em questão intitulou-se: "Eu ainda não tinha conseguido nomear" e contou com cerca de 80 participantes num trabalho com duas horas e meia de duração, vivenciado no Centro Cultural São Paulo, em 18 de agosto de 2018. As cenas que dispararam o conteúdo espontâneo se referiam àquelas situações que não conseguimos nomear, em que falta ou não cabe a palavra; situações que nos surpreendem ou que provocam um alto impacto emocional.

O trabalho, no qual atuei como diretora, contou com a atuação de "egos auxiliares", função exercida durante a atividade por membros do grupo Gota D'água e por estudantes da disciplina Ego Auxiliar, ministrada por mim, autora da pesquisa, durante o primeiro semestre de 2018, para alunos em formação na área de Psicodrama do Departamento de Psicodrama do Instituto Sedes Sapientiae (DPSedes).

A seguir, as sessões são descritas conforme a sucessão de partes que as compõem, a fim de contextualizar o recorte que pretendo analisar mais adiante para investigar os efeitos psicoterapêuticos do que aconteceu ao longo desse processo.

\section{Aquecimento}

Atores da equipe estão sentados na plateia, criando uma aproximação de horizontalidade com o público espontâneo. Na direção, optei por trabalhar com o mínimo de interrupção e fazer com que a cenografia propiciasse um espaço de fluência para reproduzir a experiência de estar em cena. Assim, o aquecimento foi ininterrupto. As cenas ensaiadas iniciaram-se a partir do círculo central com os atores voltados para a plateia, buscando facilitar a interação. Entrando e saindo do centro, os atores criavam uma onda giratória e um equilibrio de forças centrípetas e centrífugas, abrindo dois campos: um que jogava as cenas para o público e outro que se voltava para o particular de cada história narrada. Segundo afirma Alves (1997,p. 101), quando estabelece diferenças entre arte e psicodrama:

O psicodrama é centrípeto, quando através da ação dramática "penetra a alma" em busca de alguma verdade, estamos buscando o "status nascendi", padröes relacionais; já a arte é centrifuga: ela sai de um determinado "estado de alma" do artista, para alcançar, digamos, o mundo.

Com o dispositivo do grupo Gota D'água, é possível caminhar nessas duas direções. O espaço cenográfico operou como um dinamizador da cena e promoveu um intenso processo de criação. Os dramas apresentados nesse jogo de forças ganharam poesia também no singular, com o que pôde ser desnudado de cada um, no que se ofereceu como potencial de transformação.

\section{Dramatização}

As quatro cenas se alternaram entre o cômico e o risível e entre momentos de dor e de angústia. Destaco duas delas, que trouxeram uma atmosfera densa e ambivalente em torno das relações pai-filho. De acordo com Perazzo (2012, p. 89), 
“o objetivo maior do psicodrama é promover a incorporação da verdade psicodramática e poética de cada um”. As cenas que traziam situações de difícil nomeação permitiram acessar vozes antes inaudíveis.

Os participantes da plateia, ao entrar em cena, experimentaram responder de novas formas a cenas de suas vidas. Muitos deles produziram cenas de alto impacto, mas destaco a atuação daquele que chamarei pelo nome fictício de Celso, por trazer o tema protagônico revelando novos vértices e intensidades para o grupo, o que o legitimou na produção. A escolha desse participante-protagonista deu-se por entender que ele trouxe o tema protagônico em uma participação que produziu intensa mobilização grupal. Após a experiência coletiva, convidei Celso para realizar quatro sessões individuais comigo, durante as quais foi possível organizar o material produzido, elaborar e ressignificar o que ele viveu no grupo e olhar para os efeitos transformadores e psicoterapêuticos obtidos.

\section{Participação de Celso na cena 1: “Eu ainda não tinha conseguido nomear"}

A cena, previamente produzida pelo grupo, trouxe o conflito da relação entre pai e filho marcado por desqualificações do pai quanto às opções profissionais do filho. O efeito do enfrentamento com o pai e esse incômodo foi encenado com um duelo de palavras que aconteceu em um ringue de boxe, construído com quatro atores sustentando um elástico no ar. O formato de ringue retangular estabeleceu uma delimitação dos campos de força de poder que fazem emergir as tensões antagônicas.

Convoquei os participantes da plateia para propor desdobramentos a partir dessa cena original, pedindo-lhes que assumissem o papel de pai ou de filho, dando continuidade espontaneamente à trama inicialmente apresentada. Mais do que os golpes simulados, o que estava em jogo era o diálogo construído ao longo da movimentação. O que não podia ser dito na realidade ganhou espaço de fala no "como se". Celso pediu para desempenhar o papel do pai e se dirigiu ao "filho", então, num gesto de sufocamento disse: "Morra?", ao que o ego auxiliar, no papel de filho, respondeu: "Você não vai conseguir me matar!'

Identificado no papel de pai, Celso termina a cena nocauteando o filho. Ao experimentar ser o filho, na inversão de papéis, disse ser mais forte, mas mesmo assim não reagiu de forma eficiente e, ao final da cena, também terminou nocauteado pelo pai. Ou seja, em ambas as posições vivenciou o autoritarismo e a preponderância da força paterna. Curiosamente, foram os outros participantes, ao assumirem o papel de filho, que puderam desconstruir as falas autoritárias e arbitrárias daquele pai.

Como diretora do ato, dirigi-me ao grupo maior para pedir ressonâncias do ato junto à plateia, que referendou a cena com as seguintes falas: "Covarde"; "Abuso de poder"; "Você não vai conseguir me matar"; "Autoritário"; "Luto"; "Eu finjo que você vai ganhar de mim”; "Eu estou no chão, mas você não vai me derrubar". Pedi-lhes, então, para que avançassem a cena de forma não verbal e retirei a palavra para preservar a emoção nos corpos e intensificar a força dramática da cena. Já a espontaneidade e a criatividade da cena vivida integram, na cena psicodramática palavra, sentimento e expressão.

\section{Participação de Celso na cena 2: "Eu sou sua filha, vim te ver”}

A cena original trazia a relação pai-filho(a) e o afastamento do pai após a separação conjugal. Surge uma filha que tenta resgatar esse pai perdido em sua história. A frase que ecoa na cena é: "Eu sou sua filha, eu vim te ver" e se desdobra para o trabalho psicodramático em novas cenas que ressignificam essa relação. Perdão e reparação são temas recorrentes. Todos se movimentam, as cenas são feitas de maneira concomitante e os participantes se alternam nos papéis, ora de pai, ora de filho(a).

Neste segundo momento, Celso criou o personagem de um lenhador que se prepara para cortar uma árvore. O ego auxiliar da plateia faz o papel de árvore. O lenhador está com raiva, por isso, corta as raízes da árvore até derrubá-la. Depois vai para cima dela no chão, olha-a fixamente para confirmar a sua morte. $\mathrm{O}$ ator no papel de árvore abatida continua distante, indiferente e imóvel. Celso se deitou no chão como quem descansa de esgotamento provocado pela cena. Aproximo-me e tento investigar um pouco mais sobre a cena: é uma continuidade da cena do ringue? Uma resposta à violência do pai?

Celso continua deitado no chão, braços e pernas formando uma estrela com o corpo. Observo-o estendido no chão, escuto que precisa de um tempo e não quero ir além do que já fizemos. "Precisa de algo mais?", perguntei. "Não", foi a resposta. 
O sentimento que Celso verbaliza é o de alívio. Novamente, peço desdobramentos à plateia. Outros participantes assumem os papéis de lenhador e de árvore, dando voz ao inaudível. As cenas ressoam no grupo e um texto, que até então não podia ser dito pelo protagonista, ganha expressões de natureza diversa: raiva, amor, impossibilidades.

Em ambas as cenas em que Celso atuou, a morte pareceu ser a única possibilidade de ação. Não há reparação, não há elaboração. Apesar de tudo, há alguma diferença entre essas cenas, porque, na segunda, de alguma forma, ele "vence o pai”, um pai que está no seu imaginário. Há um corte radical, um estado de extrema tensão sucedida pela sensação de alívio, uma tentativa, via catarse, de "extrair" o problema, possibilitada pelo ato de cortar a árvore. Trata-se de algo que Celso pôde viver e sentir profundamente com e pelo grupo.

\section{Compartilhar}

Mediante o compartilhamento, muitos foram os relatos sobre a experiência e os sentimentos gerados nas evocações de relação pai-filho(a): saudades, gratidão, desencontros, esquecimentos, reparações. A cena de uma filha em busca do paradeiro do pai foi bastante citada pelos participantes, e cada um pôde relatar sua vivência em relação à filiação.

\section{SESSÕES DE ATENDIMENTO PÓS-ATO SOCIONÔMICO}

O objetivo das quatro sessões individuais posteriores oferecidas a Celso foi ampliar os sentidos e significados que o ato socionômico trouxe para esse participante e conhecer os efeitos das cenas vividas em sua esfera privada, permitindo a ele revisitálas. Segundo Aguiar (1998, p. 135), dramatizar implica a busca de um novo saber.É sempre uma aventura porque não se sabe o que se está procurando. É com esse espírito que percorremos as cenas, revisitamos os personagens, associamos a produção das cenas a fatos e emoções da vida do protagonista.

Assim, nos encontros individuais, trabalhou-se a partir das cenas produzidas, e se ampliaram os sentidos via personagens e realidade suplementar. Tomo aqui a noção de realidade suplementar formulada por Moreno: "é usada como uma técnica para completar e curar, para ter um efeito integrador sobre o ego, de forma que o participante se sinta melhor e consiga tocar a sua vida de maneira mais saudável" (Moreno et al., 2001, p. 45). Dessa forma, um diálogo construído no aqui-agora espontâneo atualiza e pode curar velhas feridas num campo intermediário entre a fantasia e a realidade. Nessa medida, cabe ao contexto dramático propiciar novas versões que incorporem outras leituras da cena revisitada.

Na primeira sessão, agora como psicoterapeuta, pedi a Celso que me contasse um pouco sobre os efeitos que experimentou no ato público. Sobre a cena 2 do ato socionômico, em que criou o personagem lenhador, ele relatou:

A cena do lenhador, apesar de sua intensidade, do forte sentimento de raiva, me fez sentir feliz, através da arte, da criação no momento. A violência se dissipa, a nudez do ato simbólico transforma dor em cores internas, intensas, que vibram no palco aberto dentro e fora de mim.

Nesse comentário, Celso já aponta para o que há de mais vital no trabalho psicodramático: a criação. A criação no presente ressignificou sua dor. Ele continua:

Quando derrubo a árvore, simbolizo a figura do pai que eu tive, mas que não foi modelo, que não quero ser. Destruir essa imagem dentro de mim me libertou da dor que o abandono que esta relação provoca. A violência do ato com o machado é a morte que procuro levar para a imagem desse pai, que não quero ser, aquele que me abandona.

A força de cena em um único golpe fez com que descobrisse algo de si: "Eu não quero isso". O corte da raiz, que dizia respeito ao pai que o abandonou, deixa claro aquilo que ele não quer ser. Trata-se de um modelo a abandonar. 
Celso contextualizou a separação dos pais e o quanto isso foi desestruturador: ele é o segundo entre três filhos, tinha 13 anos, e o único filho a ficar morando com a mãe, que trabalhava fora e o deixava sozinho em casa. Seus outros dois irmãos foram morar com outros parentes da familia.

Relatou, ainda, ter ficado em uma espécie de "limbo" por oito anos (dos 13 aos 21 anos), sem saber direito o que fazer, aventurando-se na vida sem laços sociais significativos. É sua a associação da sensação de "limbo" com a inação, com a falta de trocas significativas. Tal sensação de espera, de fixidez, de aridez, acompanhou-o nas cenas produzidas durante o ato público e nas sessões individuais.

Proponho, nas sessões seguintes, retomar a cena do lenhador. Procuro explorar um pouco as características do cenário que ele descreveu como um lugar sombrio, vazio, mas onde há a presença de um riacho. Surgem então novos personagens e símbolos que foram trabalhados ao longo das sessões individuais. Personagens que puderam dialogar com a aridez da floresta sem vida. Um deles é um menino que traz a dimensão do lúdico e da aventura para o protagonista. Após algumas entrevistas com os diversos personagens e de exercitar as inversões de papéis, Celso se dá conta de que não quer mais conviver com o "lenhador" e com a "árvore" da mesma maneira dentro dele. O pai que aparecera no ato socionômico, na verdade, é um aspecto que Celso não quer mais para si.

Tanto o lenhador como o lutador de boxe são personagens de enfrentamento que Celso leva consigo para futuro. Na última sessão, proponho um fechamento trazendo para a cena psicodramática os personagens vividos por Celso e como eles se articulam agora dentro dele. Para concluir, Celso enuncia uma cena final na qual interpreta um viajante que sai por uma floresta levando um pouco desses "personagens" em uma mochila, para se aventurar rumo ao desconhecido. São personagens criados a partir de seu mundo interno, nos quais reconhece atributos de sua personalidade: o lenhador é a sua coragem; o homem da capa preta é seu lado misterioso; o lutador de boxe é quem dá socos e obtém respostas práticas e objetivas; a árvore e suas raízes podem também fornecer-lhe nutrientes para seguir; o menino representa a ludicidade, a fantasia para que continue a sonhar.

Ao final, Celso relata ter podido ampliar seu repertório de possibilidades por meio desses personagens e se deslocar de uma posição de estagnação para uma de maior movimento.

\section{Discussão das sessões}

Celso pôde, nessas quatro sessões, entrar em contato com personagens que habitam seu mundo interno e que ainda não tinha nomeado. O personagem pai-árvore, inanimado, remete inicialmente a um pai rígido, imóvel, impassível, que ele quer destruir assim como aquilo que considera estagnado, imóvel dentro de si. Esse personagem se liga a um papel imaginário, vivido em sua imaginação, e que, segundo Perazzo (1999, p. 138), seria, portanto, conservado dentro do sujeito. Em cena, quando pôde, no papel psicodramático, viver o personagem do "lenhador" que corta com "muita intensidade" a raiz da árvore, a mesma que o ligava à fantasia desse pai imaginário - inerte, estagnado —, viveu em cena uma "explosão, criativa e espontânea, de papéis que não podiam ser atuados por estarem cristalizados transferencialmente” (Perazzo, 1999, p. 139). Esse foi um momento catártico, ou seja, uma ação em cena de extrema liberação afetiva para ele e para a plateia que o acolheu o legitimou no cenário psicodramático.

Foi um passo em direção à integração de aspectos que, inicialmente, não eram conscientes. Ele observou o personagem árvore e nomeou dois aspectos dele mesmo, um lado estagnado e outro liberto, móvel. Associou ao personagem pai-árvore um pai que não gostaria de ser hoje. Não pode mudar a relação que teve com o pai real, mas pode cortar as raízes que o ligam àquele modelo e à dor de abandono.

O que fica evidente não é só a ausência do pai, mas a existência de um desejo e a urgência de se reinventar manifesta em um desassossego diante do mundo através do outro, com o outro, na potência das relações. Os demais personagens construídos nas cenas de entre "fantasia e realidade" encarnam desejos e oferecem novos recursos para que Celso continue o seu caminhar.

\section{CONSIDERAÇÕES FINAIS}

Constatei, nas sessões individuais realizadas com Celso, após a atividade psicodramática pública, que ocorreram efeitos psicoterapêuticos significativos permitindo que ele ressignificasse os personagens vividos no ato socionômico, representados em campo intenso, quase sem palavras, só com a força da emoção em ato, para depois redimensioná-lo em seu mundo psíquico por meio das sessões psicoterapêuticas. 
Apostar na poesia da cena teatral, portanto, valida o trabalho do dispositivo do grupo Gota D'água, que tem como vértice metodológico o teatro espontâneo e a estética do drama, que, para além de uma proposta socioeducativa, permitiu verificar os efeitos psicoterapêuticos desse trabalho por meio da reinvenção da dor, contornando o inominável e singular da vida.

\section{DISPONIBILIDADE DE DADOS DE PESQUISA}

Não se aplica.

\section{FINANCIAMENTO}

Não se aplica.

\section{AGRADECIMENTOS}

A Laerte Fernandes (in memorian), meu querido pai, que me ensinou o laço com as palavras.

\section{REFERÊNCIAS}

Aguiar, M. (1998). Teatro espontâneo e psicodrama. Ágora.

Aguiar, M. (2011). Psicodrama: Ética, estética e terapêutica. In J. MOTTA (Org.), Psicodrama: Ciência e arte (pp. 5568). Ágora.

Alves, L. F. (1997). Psicodrama e Arte. Revista Brasileira de Psicodrama. 5(1), 101-106.

Fernandes, C. C. (2010). Teatro espontâneo: O território do grupo Gota D'água. [Monografia, Instituto Sedes Sapientiae].

Davoli, C., Batista, M., \& Nilson, S. (2012). Psicodrama público e direção de grandes grupos. In M. P. Nery, \& M. I. G. Conceição (Orgs.), Intervençôes grupais: O psicodrama e seus métodos (pp. 173-193). Ágora.

Dedomenico, A. M., \& Fernandes, C. (2012). Pistas contemporâneas em socionomia. In: M. P. Nery \& M. I. G. Conceição (Orgs.), Intervenções grupais: O psicodrama e seus métodos (pp. 195-212). Ágora.

Neto, A. (2011). O espaço cênico no psicodrama. In J. Motta (Org.), Psicodrama: Ciência e arte. (p. 26). Ágora.

Mascarenhas, P. (2008). Psicodrama no Centro Cultural São Paulo. Revista Brasileira de Psicodrama. 16(1), 63.

Merengué, D. (2017). Fronteiras. http://artepsicodramafilosofia.blogspot.com/

Moreno, Z. T., Blomkvist, L., \& Rutzel, T. (2001). A realidade suplementar e a arte de curar. Ágora.

Perazzo, S. (1999). Fragmentos de um olhar psicodramático. Ágora.

Perazzo, S. (2012). Psicodrama grupal. In M. P. Nery \& M. I. G. Conceição (Orgs.), Intervenções grupais: O psicodrama e seus métodos (pp. 195-212). Ágora.

Renonês, A. (2008). Escritos abertos: Interpretação, momento, identidade. Saber e Saúde.

Rodrigues, R. (2008). Quadro de referência para intervenções grupais psicodramáticas. Revista Brasileira de Psicodrama. 16(1), 75 